\title{
Thyroglobulin Determined in Thyroid Fine Needle Aspiration Biopsies by Radial Immunodiffusion and Electroimmunodiffusion
}

\author{
Giovanni Battista Salabè, Luciano Corvo and Helga Lotz
}

Istituto di Medicina Sperimentale del C. N. R., Roma, Italy

\begin{abstract}
Summary: Radial immunodiffusion and electroimmunodiffusion were used to measure thyroglobulin, the main component of thyroid colloid, in thyroid fine needle aspiration biopsies. A linear relationship was established between precipitation ring diameter and thyroglobulin concentration by radial immunodiffusion $(0.5-3.0 \mathrm{~g} / \mathrm{l})$, and between "rocket" height and thyroglobulin concentration by electroimmunodiffusion $(0.1-2.0 \mathrm{~g} / \mathrm{l})$. A nearly complete correlation was observed between the two methods $(r=0.97)$. In radial immunodiffusion the ring diameter is dependent on time of diffusion and on the antiserum concentration in the agar gel. In this study, the observation time was standardised at $48 \mathrm{~h}$, and the rabbit anti-thyroglobulin serum concentration at $26 \mathrm{ml} / \mathrm{l}$. The intrathyroidal concentration of thyroglobulin was determined by radial immunodiffusion and the thyroid fine needle aspiration biopsy of 45 thyroid tumours with different cytological-laboratory- and clinical diagnoses. It was found that in colloid nodules or cysts thyroglobulin is markedly higher than in euthyroid nodular goitre $(13.7 \pm 11.9 \mathrm{~g} / \mathrm{l} \mathrm{vs} 1.35$ $\pm 0.8 \mathrm{~g} / \mathrm{l}, \mathrm{p}=0.005$ ).

In conclusion radial immunodiffusion and electroimmunodiffusion are precise, easy to perform, low cost, non polluting methods, which do not require high sample dilution (in contrast, high sample dilution is necessary for measurement of thyroglobulin in thyroid fine needle aspiration biopsy by radial immunodiffusion). Measurement of thyroglobulin in thyroid fine needle aspiration biopsy provides a quantitative estimate of colloid, an important marker in the differential diagnosis of thyroid nodules.
\end{abstract}

\section{Introduction}

Methods of immunoprecipitation in agar have been widely employed to measure protein antigens in serum and other biological fluids $(1-6)$. Various immunometric assays have been developed to measure thyroglobulin but none of them is based on an immunoprecipitating reaction $(7,8)$. Immunoprecipitation methods for thyroglobulin have been neglected, because they are very specific but of low sensitivity and therefore not suitable for measuring thyroglobulin in serum which is the main tumour marker in the follow up of differentiated thyroid carcinoma. The widespread use of thyroid fine needle aspiration biopsy indicated the importance of colloid in the smears as a landmark of tissue differentiation $(9-11)$. Colloid is currently described by the cytologist as "bluish/violet diffuse background or droplets and strands of granular material" (12) but cannot be quantitatively measured in thyroid fine needle aspiration biopsy. Thyroglobulin, the major component of colloid (13), could provide a quantitative evaluation. We have used immunoprecipitation methods (radial immunodiffusion, electroimmunodiffusion) for the measurement of thyroglobulin and found them to be simple, inexpensive and rapid; most importantly, they are suitable for the measurement of thyroglobulin in thyroid fine needle aspiration biopsy.

\section{Methods}

Thyroglobulin preparation

Thyroglobulin was purified from a crude saline extract of a euthyroid goitre (14-16). Immediately after surgery the extract was processed in phosphate buffered saline: $\mathrm{NaCl} 150 \mathrm{mmol} / \mathrm{l}$, phosphate buffer $10 \mathrm{mmol} / \mathrm{l}$, pH 7.4, containing $2 \mathrm{mmol} / \mathrm{l}$ diisopropylfluorophosphate or aprotinin (final concentration $0.5-3 \times 10^{6} \mathrm{KIU} / \mathrm{l}$ ) (17). Thyroglobulin was purified from the extract by repeated chromatography on a column of Sepharose 6B (Pharmacia, Uppsala, S). Fractions of the peak were pooled, adjusted to $1 \mathrm{~g} / \mathrm{l}$ and stored at $-20^{\circ} \mathrm{C}$ with sodium azide $(5 \mathrm{mmol} / \mathrm{l})$ until used. Non-reducing SDS-PAGE showed a single band of about $M_{\mathrm{r}} 300$ (18).

\section{Course of immunization}

Two New Zealand white rabbits received foot pad injections of thyroglobulin emulsified in complete Freund's adjuvant $(1+1$, by vol.). The animals were given $1 \mathrm{mg}$ of thyroglobulin for each foot pad. After 5 weeks the rabbits were boosted with a further $4 \mathrm{mg}$ thyroglobulin and 2 weeks later blood was drawn by cardiac puncture. The anti-thyroglobulin antiserum was stored in $0.5 \mathrm{ml}$ aliquots at $-20^{\circ} \mathrm{C}$ in $\mathrm{NaN}_{3}(5 \mathrm{mmol} / \mathrm{l})$.

Titre and specificity of rabbit anti-thyroglobulin antiserum

Titre was determined by the equivalence of a precipitating curve: the first rabbit gave a maximal precipitating capacity for thyroglobulin of $10 \mathrm{~g} / 1$, the second rabbit a capacity of $20 \mathrm{~g} / \mathrm{l}$. The second antiserum was used in all experiments. The specificity of the scra was assayed by immunoelectrophoresis using agarose plates (Technicon U.S. A.). The two anti thyroglobulin sera gave a single precipitation arc with purified thyroglobulin or thyroid extract. Rabbit 
anti-human serum gave no reaction with thyroglobulin, but a normal pattern with normal human serum.

Preparation of the thyroid fine needle aspiration biopsy sample for evaluation by radial immunodiffusion or electroimmunodiffusion

A fraction of the aspirate $(30 \mu \mathrm{l})$ was diluted $1+1$ with phosphate buffered saline and centrifuged in polyethylene tubes $(29 \times 6 \mathrm{~mm})$ $2 \mathrm{~min}$ at $1000 \mathrm{~g}$. The supernatant was employed for the quantitative determination of thyroglobulin. In the case of cysts an aliquot of the fluid $(0.1-0.3 \mathrm{ml})$ was centrifuged $(5 \mathrm{~min}$ at $1000 \mathrm{~g})$, the supernatant was employed for the quantification of thyroglobulin, and the sediment was submitted to cytological examination.

\section{Radial immunodiffusion}

Gel plates were prepared by mixing $15 \mathrm{~g} / \mathrm{l}$ agarose gel solution with different amounts of rabbit anti-thyroglobulin serum (10-50 $\mathrm{ml} / \mathrm{l}$ ) at $56^{\circ} \mathrm{C}$, and pouring $12 \mathrm{ml}$ on the hydrophilic side of a gel plate $(7 \times 8 \mathrm{~cm})$ (Gel Bond film, Pharmacia). Sixteen wells were cut into the gel with a $2.5 \mathrm{~mm}$ suction needle equipped with a telescopic device (Behring, Marburg, D). Standards and samples $(5 \mu \mathrm{l})$ were applied immediately afterwards with an Eppendorf precision pipette (imprecision $<2.8 \%$ ) and incubated at different time intervals in a moist chamber at $21^{\circ} \mathrm{C}$. Precision measurement of the unstained precipitation ring was obtained by a magnification device (C. Roth, Karlsruhe, D). Two diameters at right angles to each other are read and averaged. Duplicates agreed within $5 \%$. The standard curve was plotted with the square of the diameters on the ordinate and the concentration of thyroglobulin on the abscissa. After reading, the gels were dried and stained with Coomassie Blue.

\section{Electroimmunodiffusion}

Gel plates were prepared by mixing $10 \mathrm{~g} / \mathrm{l}$ agarose gel solution in $80 \mathrm{mmol} / \mathrm{l}$ tris-borate buffer $\mathrm{pH} 8.6$ with $20 \mathrm{~g} / \mathrm{l}$ dextran $M_{\mathrm{r}} 70000$ and $10 \mathrm{ml} / \mathrm{l}$ rabbit anti-thyroglobulin serum at $56^{\circ} \mathrm{C}$. Eight $\mathrm{ml}$ were poured on the hydrophilic side of a Gel Bond. The plates were allowed to stand at $4{ }^{\circ} \mathrm{C}$ for $2 \mathrm{~h}$ and prepared as described for radial immunodiffusion with 11 wells; standard and samples $(5 \mu \mathrm{l})$ were applied immediately afterwards. Gels were run in tris-borate buffer $80 \mathrm{mmol} / \mathrm{l}$, at $\mathrm{pH} 8.6$ for $14 \mathrm{~h}$ at $12 \mathrm{~V}$ constant (Rapidophor M3, Immuno, Wien, A). Height of rockets was measured with an electroimmunodiffusion reader. The standard curve was constructed by plotting rocket heights measured at half width on the ordinate and thyroglobulin concentration on the abscissa. Radioimmunoassay of thyroglobulin was performed with a commercial kit (Techland, Liège, Belgium). Statistical analysis was carried out using Multistat (Biosoft, Cambridge, U.K.).

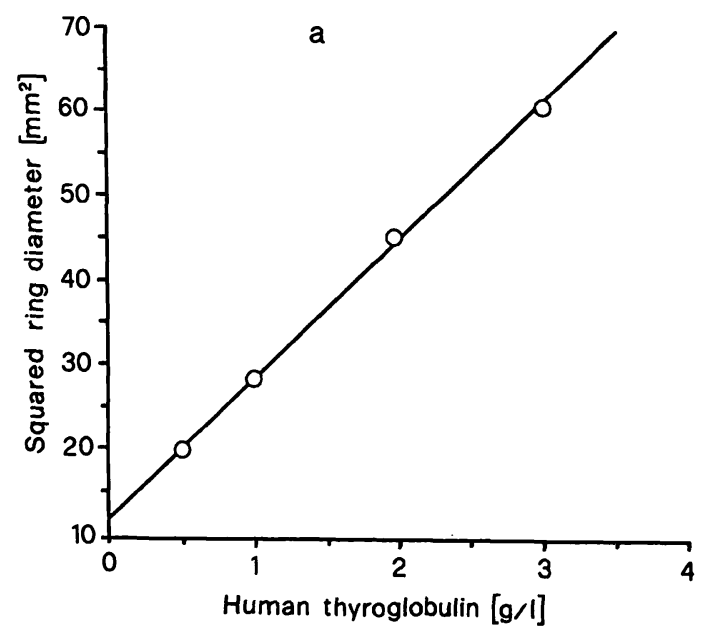

\section{Results}

Radial immunodiffusion showed a linear relationship between the square of the ring diameter and thyroglobulin concentration from 0.5 to $3 \mathrm{~g} / \mathrm{l}$. At higher concentrations, the increase of the square of the ring diameter in radial immunodiffusion is no longer linear when the standard time of ring development $(48 \mathrm{~h})$ is used (fig. 1a). In seven experiments carried out on different days, the coefficient of variation (CV) around the points of the standard curve was between $3.3 \%$ and $13.8 \%$ (tab. 1). By electroimmunodiffusion, a linear relationship was observed between height - measured at half width of the rockets - and thyroglobulin concentration from 0.1 to $2 \mathrm{~g} / \mathrm{l}$ (fig. $1 \mathrm{~b}$ ). The sensitivity of electroimmunodiffusion is higher than that of radial immunodiffusion $(0.1$ vs $0.5 \mathrm{~g} / \mathrm{l})$. Figure 2 shows the correlation between electroimmunodiffusion and radial immunodiffusion for the measurement of thyroglobulin concentrations in 20 thyroid fine needle aspiration biopsies. A nearly complete agreement was observed between the two methods, with correlation coefficient of 0.97 (fig. 2). A good cor-

Tab. 1 Radial immunodiffusion: Ring diameter squares $\left(\mathrm{mm}^{2}\right)$ of thyroglobulin concentrations $(0.5-4.0 \mathrm{~g} / \mathrm{l})$ in 7 reference curves

\begin{tabular}{lclllr}
\hline $\begin{array}{l}\text { Thyro- } \\
\text { globulin }(\mathrm{g} / \mathrm{l})\end{array}$ & 0.5 & 1 & 2 & 3 & \multicolumn{1}{l}{4} \\
\hline $\begin{array}{l}\text { Experiment } \\
\text { no. }\end{array}$ & \multicolumn{5}{l}{ Ring diameter squares $\left(\mathrm{mm}^{2}\right)$} \\
\hline I & 21. & 24.0 & 45.0 & 62.4 & 75.0 \\
II & 19.8 & 29.0 & 45.0 & 64.0 & 65.0 \\
III & 17.0 & 31.8 & 48.0 & 57.8 & 76.6 \\
IV & 18.2 & 28.4 & 54.6 & 59.8 & 71.4 \\
V & 24.6 & 34.0 & 48.0 & 57.2 & 74.6 \\
VI & 20.2 & 28.1 & 43.5 & 61.0 & 73.9 \\
VII & 17.6 & 23.0 & 42.2 & 59.3 & 65.6 \\
mean & 19.8 & 28.3 & 46.6 & 60.2 & 72.4 \\
S.D. & \pm 2.5 & \pm 3.9 & \pm 4.1 & \pm 2.4 & \pm 4.0 \\
CV (\%) & 12.6 & 13.8 & 8.7 & 3.3 & 5.5 \\
\hline
\end{tabular}

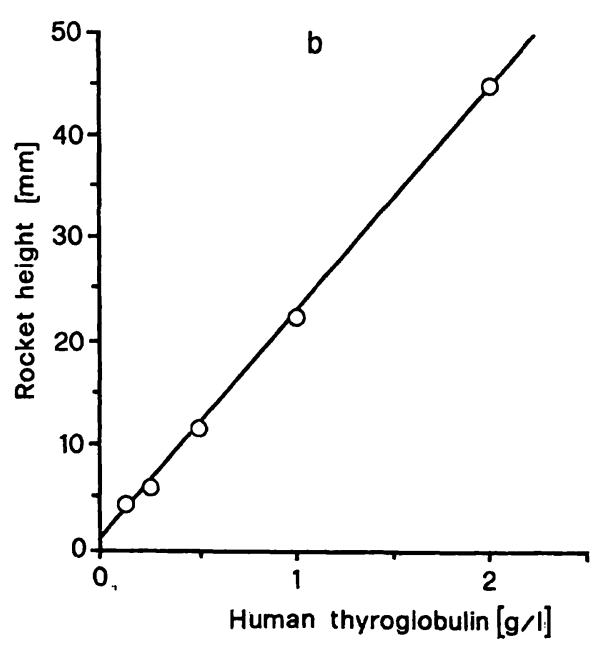

Fig. 1 Standard curves

a) Radial immunodiffusion $y=13.6+15.1 x ; r=0.99$

b) Electroimmunodiffusion $y=0.7+22.0 x ; r=0.99$ 


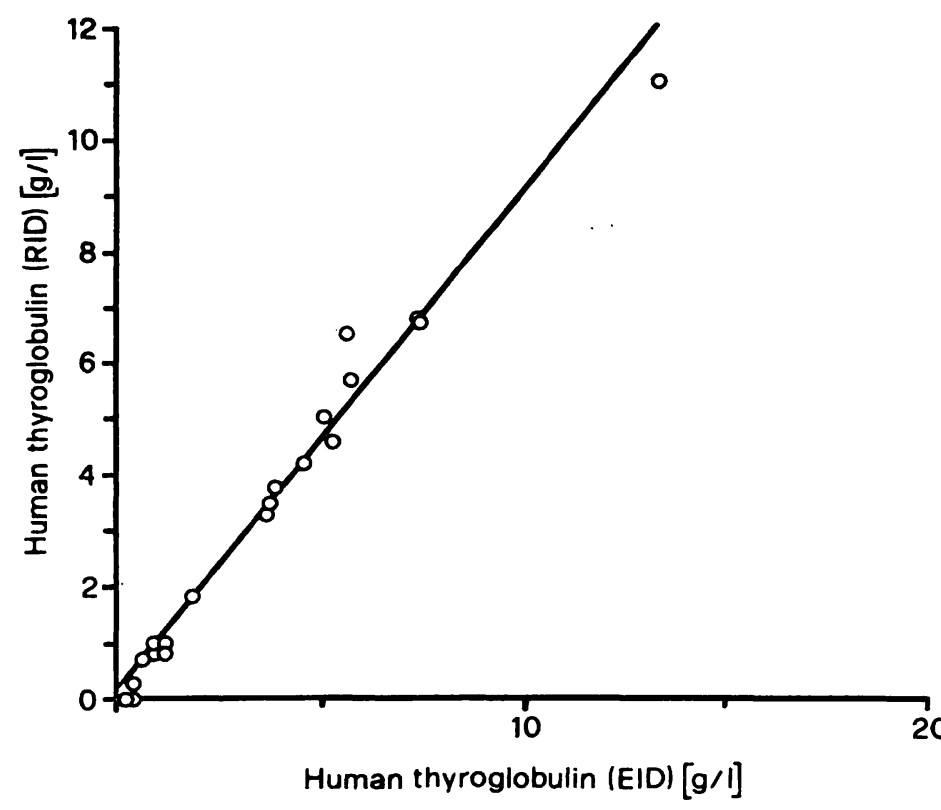

Fig. 2 Correlation between radial immunodiffusion and electroimmunodiffusion of thyroglobulin in thyroid fine needle aspiration biopsy.

$\mathrm{y}=0.12+0.89 \mathrm{x} ; \mathrm{r}=0.97$

Samples were from colloid nodules or haemorrhagic pseudocysts.

relation was also found between radioimmunoassay and radial immunodiffusion $(r=0.82 ; p=0.003)$. In radial immunodiffusion the ring diameter is dependent on time of diffusion and on the antiserum concentration in the agar gel. In order to choose optimal conditions we performed a more detailed study of the effect of the above mentioned variables. The growth of the ring diameter as a function of time and thyroglobulin concentration at a fixed thyroglobulin antiserum concentration $(26 \mathrm{ml} / \mathrm{l})$ is shown in figure 3a. At low thyroglobulin concentration - up to $2 \mathrm{~g} / \mathrm{l}$ - the ring approaches the end point after $48 \mathrm{~h}$, whereas at 3 and $4 \mathrm{~g} / 1$ thyroglobulin the ring approaches the end point of precipitation after 4 days. In figure $3 b$ ring growth is evaluated as a function of time and thyroglobulin antiserum concentration at a fixed amount of thyroglobulin of $4 \mathrm{~g} / \mathrm{l}$. We observed the expected inverse relationship between rabbit anti-thyroglobulin concentration and the diameter of the precipitation ring (1). The end point of the precipitate diffusion is attained earlier in the more concentrated sera. In a given assay, the observation time and the titre of the rabbit anti-thyroglobulin antiserum, together with its concentration, are crucial conditions for optimal ring diameter; we therefore chose $26 \mathrm{ml} / 1$ rabbit anti-thyroglobulin antiserum and $48 \mathrm{~h}$ time of incubation at room temperature in a moist chamber. Intrathyroidal concentrations of thyroglobulin determined by radial immunodiffusion in the thyroid fine needle aspiration biopsy of 45 thyroid nodules with different cytological, laboratory and clinical diagnosis are shown in table 2. In euthyroid nodular goitre thyroglobulin was in the range of our reference curve $(1.35 \pm 0.8 \mathrm{~g} / \mathrm{l})$. In colloid nodules or cysts thyroglobulin was significantly higher $(1.35 \pm 0.8 \mathrm{~g} / \mathrm{l}$ vs 13.7 $\pm 11.9 \mathrm{~g} / \mathrm{l} ; \mathrm{p}=0.005$ ) than in euthyroid nodular goitre, and the sample had to be diluted. Concentrations comparable to those of the euthyroid nodular goitre were observed in haemorrhagic pseudocysts $(1.68 \pm 0.7 \mathrm{~g} / \mathrm{l})$. In 6 samples of smears, considered inadequate for cytologic diagnosis, thyroglobulin was $1.42 \pm 0.93 \mathrm{~g} / \mathrm{l}$ (satisfactory smears: at least 10 cell clusters each comprising more than 20 cells). The radial immunodiffusion method thus gave some indication of the nature of the nodule in insufficient smears. In patients with a diagnosis of hyperfunctioning nodule, chronic lymphocytic thyroiditis, follicular adenoma and Graves' disease the intrathyroid concentration of thyroglobulin was not measurable by radial immunodiffusion. This is in good
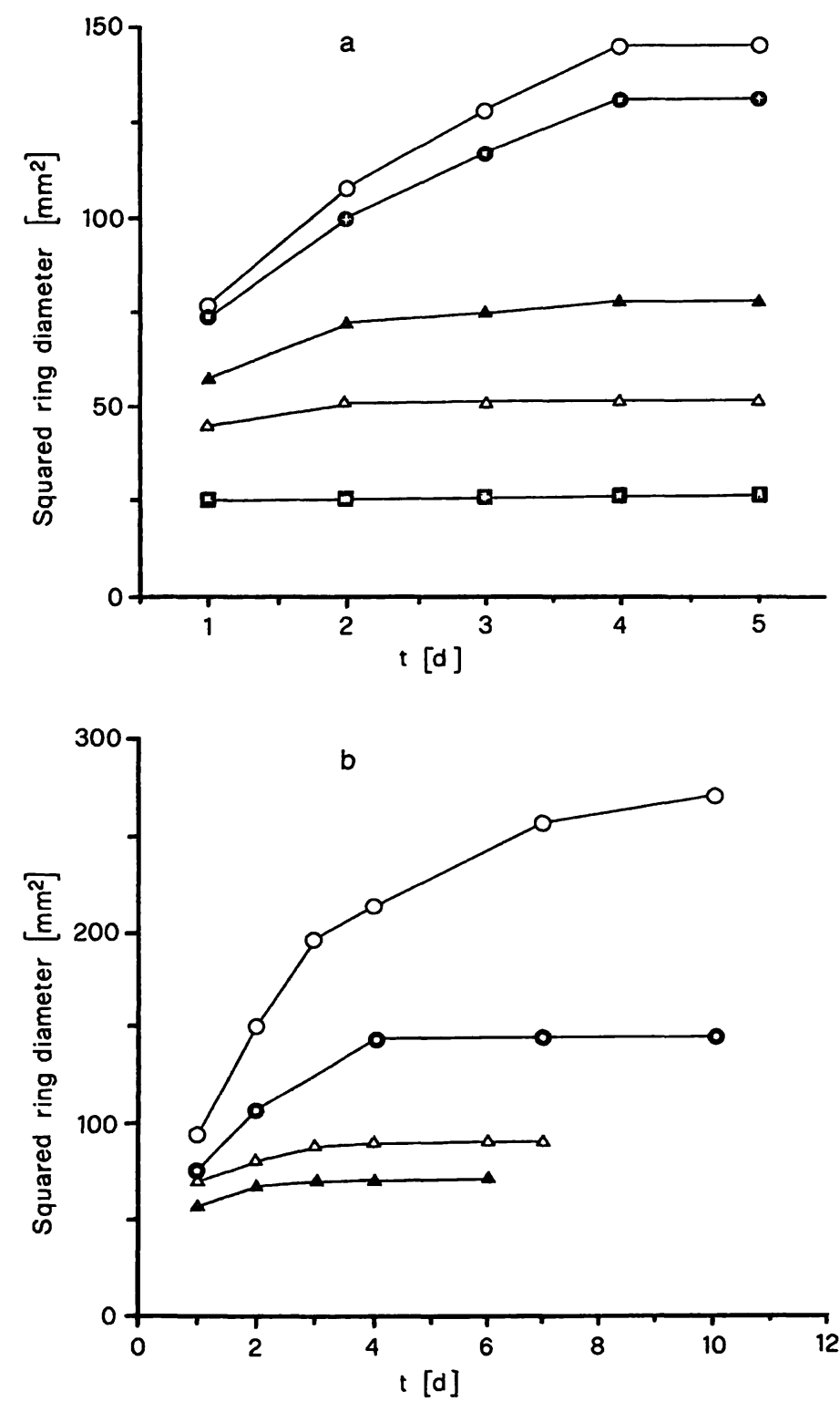

Fig. 3 Growth of ring diameter in radial immunodiffusion:

a) as a function of time and thyroglobulin concentration at a fixed concentration of rabbit-anti-thyroglobulin $(26 \mathrm{ml} / 1)$.

$-\square-$ thyroglobulin $0.5 \mathrm{~g} / \mathrm{l} ; \quad-\Delta-$ thyroglobulin $1.0 \mathrm{~g} / \mathrm{l}$ $-\Delta-$ thyroglobulin $2.0 \mathrm{~g} / \mathrm{l} ; \quad-0-$ thyroglobulin $3.0 \mathrm{~g} / \mathrm{l}$; - 0 - thyroglobulin $4.0 \mathrm{~g} / \mathrm{l}$.

b) as a function of time and thyroglobulin antiserum concentration at a fixed thyroglobulin concentration $(4 \mathrm{~g} / \mathrm{l})$.

- 0 - anti-thyroglobulin $13 \mathrm{ml} / \mathrm{l} ;-0$ - anti-thyroglobulin $26 \mathrm{ml} / \mathrm{l}$; $-\Delta-$ anti-thyroglobulin $40 \mathrm{ml} / \mathrm{l} ;-\Delta-$ anti-thyroglobulin $53 \mathrm{ml} / \mathrm{l}$. 
Tab. 2 Thyroglobulin concentrations in fine needle aspiration biopsies from different thyroid diseases by radial immunodiffusion.

\begin{tabular}{|c|c|c|c|}
\hline \multirow{2}{*}{$\begin{array}{l}\text { Diagnosis }^{\mathrm{a}} \\
\text { (Clinical, } \\
\text { cytological, } \\
\text { laboratory') }\end{array}$} & \multirow{2}{*}{$\begin{array}{l}\text { No. of } \\
\text { obser- } \\
\text { vations }\end{array}$} & \multicolumn{2}{|c|}{ Thyroglobulin } \\
\hline & & $\begin{array}{l}(g / l) \\
\text { mean } \\
\pm S D\end{array}$ & $\begin{array}{l}(\mathrm{g} / \mathrm{l}) \\
\text { range }\end{array}$ \\
\hline Euthyroid nodular goitre & 11 & $\begin{array}{r}1.35 \\
\pm 0.80\end{array}$ & $0.8-2.5$ \\
\hline Colloid nodules or cysts & 7 & $\begin{array}{r}13.77 \\
\pm 11.90^{\mathrm{b}}\end{array}$ & $5.0-40.0$ \\
\hline Haemorrhagic pseudocysts & 6 & $\begin{array}{r}1.68 \\
\pm 0.70\end{array}$ & $1.0-2.5$ \\
\hline Unsatisfactory smears & 6 & $\begin{array}{r}1.42 \\
\pm 0.93\end{array}$ & $0.6-2.7$ \\
\hline
\end{tabular}

Thyroglobulin in thyroid fine needle aspiration biopsy by radial immunodiffusion was undetectable or $<0.5 \mathrm{~g} / 1$ in chronic lymphocytic thyroiditis ( 5 cases), follicular proliferation ( 2 cases), hyperfunctioning nodule, Graves' disease (2 cases).

a Euthyroid nodular goitre: goitre with one or more nodule(s). Heterogeneous multifocal echopattern. Serum thyroid hormones normal, thyrotropin-basal and stimulated by thyroliberin normal. Thyroid fine needle aspiration biopsy: groups of otricolar cells without malignant changes; sometimes whole follicles. Regressive changes (pycnotic nuclei, macrophages) and colloid.

Colloid nodule or cyst: nodule(s), anechoic or low echogenicity in euthyroid subject. Thyroid fine needle aspiration biopsy aspiration of viscous material heavily stained blue/violet with May Grünwald Giemsa and orange, green or yellow with Papanicolaou. Colloid material can sometimes take on the characteristic of a cracking pattern.

Haemorrhagic pseudocyst: long standing or recent onset, nodule(s), echographically mixed in an euthyroid subject. Thyroid fine needle aspiration biopsy: 1 to $>20 \mathrm{ml}$ of brown fluid. Sediment: cellular debris, clusters of follicular cells with regressive changes, macrophages, lymphocytes and polymorphonuclear leukocytes in a diffuse bluish background and/or irregular fragments and strands of granular material.

Unsatisfactory smears: euthyroid patients with nodular goitre or solitary nodule. Thyroid fine needle aspiration biopsy: less than 10 clusters at least 20 cells each.

Chronic lymphocytic thyroiditis: patients with goitre, sonographic feature of thyroiditis (diffusely hypoechoic, dyshomogeneous, irregular margins), high concentration of anti thyroglobulin- and anti-thyroid peroxidase antibodies. Clinical and biochemical overt or latent hypothyroidism. Thyroid fine needle aspiration biopsy: large numbers of diffusely distributed lymphocytes, lymphoblasts and plasma cells, cellular debris, oncocytic cells.

Follicular proliferation: two cases of solitary nodule echographically solid and cold by scintigraphy. Normal levels of thyroid hormones and thyrotropin and anti-thyroid antibodies. Thyroid fine needle aspiration biopsy: high level of cellularity, moderate nuclear polymorphism of cells with variously oriented nuclei, overlapping and crowding. In one case the histology showed a follicular adenoma, in the other a microfollicular hyperplasia.

Hyperfunctioning nodule: "Hot" by scintigraphy and iso- or hypoechoic. Increased thyroid hormones, low thyrotropin. Thyroid fine needle aspiration biopsy: hyperplasia with moderate anisonucleosis, colloid was pale and scanty.

Grave's disease: Cases fullfilled clinical and laboratory criteria for the disease. When thyroid fine needle aspiration biopsy was performed patients were under treatment with methylmercaptoimidazole $(20 \mathrm{mg} /$ day $)$. Thyroid fine needle aspiration biopsy: hyperplasia, anisonucleosis, little or no colloid, accumulation of lymphocytes.

${ }^{b} \mathrm{p}=0.005$ agreement with what is already known from histological (11) and biochemical (16) studies, i. e. that colloid and soluble thyroglobulin are very low in hyperplastic, neoplastic thyroid gland and lymphocytic thyroiditis.

\section{Discussion}

Thyroglobulin was measured in the fluid of aspirated neck cysts for the differential diagnosis of thyroid and parathyroid swellings (19) and also in thyroid fine needle aspiration biopsy of neck lymph-nodes in recurrent differentiated thyroid carcinoma (20). These measurements were formerly carried out by radioimmunoassay which is far too sensitive for measuring intrathyroid thyroglobulin, so that the sample has to be diluted 10000 times. In addition, radioimmunoassay is expensive, as well as using radioactive material. Two immunoprecipitation methods, electroimmunodiffusion and radial immunodiffusion are described which are precise and suited for measuring colloid in the aspirate of thyroid fine needle biopsy. Electroimmunodiffusion is more sensitive ( 0.1 vs $0.5 \mathrm{~g} / \mathrm{l})$ and more rapid than radial immunodiffusion ( $14 \mathrm{~h}$ vs $48 \mathrm{~h}$ ), but radial immunodiffusion is cheaper and technically easier to perform and does not require electrophoresis equipment. Nodular goitre occurs frequently in the general population. It is difficult to make a precise and single percentage estimate because of the wide geographical variability and the multiplicity of the manifestations of the disease, especially in the zones of endemic goitre. However, it is possible to estimate approximately that a percentage of $5-15 \%$ of the general population is affected by nodular diseases of the thyroid. In contrast, thyroid carcinoma is a relatively infrequent carcinoma accounting for only 5 new cases per 100000 inhabitants/year (21). In recent years thyroid fine needle aspiration biopsy has been widely used as the most reliable procedure to distinguish between malignant nodules and benign lesions. Cytological analysis can however raise doubts as to the nature of thyroid tumours. The quantitative determination of thyroglobulin, the main specific constituent of the colloid, can be of great help in formulating and integrating the cytological diagnosis. It is evident that there is a need for a simple, accurate and rapid procedure for the quantitative determination of thyroglobulin in thyroid fine needle aspiration biopsy in the order of milligramms, since thyroglobulin concentrations are in the order of $10-20 \mathrm{mg} / \mathrm{g}$ of wet tissue. Radioimmunoassay procedures require enormous dilution of the sample (1:10000); they are also expensive, polluting and time consuming. Immunoprecipitation procedures described in the present article provide a simple, rapid, non-polluting and low cost method which can be used to integrate the cytological diagnosis of thyroid nodules. 


\section{References}

1. Mancini G, Carbonara AO, Heremans JF. Immunochemical quantitation of antigens by single radial immunodiffusion. Immunochemistry $1965 ; 2: 235-54$.

2. Mancini G, Nash DR, Heremans JF. Further studies on single radial immunodiffusion - Ill. Qualitative analysis of related and unrelated antigens. Immunochemistry 1970; 7:261-4.

3. Laurell CB. Quantitative estimation of proteins by electrophoresis in agarose gel containing antibodies. Anal Biochem 1966; $15: 45-52$

4. Crowle AJ. Immunodiffusion. New York: Academic Press, 1973.

5. Catty D, Raykundalia C, editors. Gel immunodiffusion, immunoelectrophoresis and immunostaining methods. A practical approach. Oxford, England: IRL Press Ltd 1988; 1:137-67.

6. Johnson AM: Immunoprecipitation in gel. In: Rose NR, Friedman H, Fahey JL, editors. Manual of clinical laboratory immunology. Washington DC: Am Soc Microbiol 1986:14-24.

7. Pacini F, Pinchera A, Giani C, Grasso L, Doveri F, Baschieri L. Serum thyroglobulin in thyroid carcinoma and other thyroid disorders. J Endocrinol Invest 1980; 3:283-92.

8. Refetoff S, Lever EG. The value of serum thyroglobulin measurement in clinical practice. J Am Med Assoc 1983; 250:2352-7.

9. Hamburger JI, Miller JM, Kini RS. Clinical-pathological evaluation of thyroid nodules. Limited edition (Private Publication: Hamburger JI) Detroit USA 1979.

10. Galvan G. Thin needle aspiration biopsy and cytological examination of hypofunctional "cold" thyroid nodules in routine clinical work. Clin Nucl Med 1977; 2:413-21.

11. Droese M. Cytological aspiration biopsy of the thyroid gland. Stuttgart-New York: Schattauer Verlag, 1980.

12. Nguyen GK, Ginsberg J, Crockford PM. Fine-needle aspiration biopsy cytology of the thyroid: its value and limitations in the diagnosis and management of solitary thyroid nodules. Pathol Annu 1991; 26:63 -91.

13. Smeds S, Anderberg B. A microgel electrophoretic analysis of the colloid in single rat thyroid follicles during thyroxine suppression. Acta Endocrinol (Copenhagen) 1977; 84:30313.

14. Gentile F, Palumbo G, Salvatore G. The origin of the electrophoretic doublet of thyroglobulin. Biochem Biophys Res Commun 1992; 186:1185-91.

15. Gärtner R, Bechtner G, Greil W, Horn K, Pickardt CR. Characterization of microheterogeneity of human thyroglobulin from different thyroid disorders, Acta Endocrinol (Copenhagen) 1985; 109:76-82.

16. Olivieri A, Marzullo A, Salabè GB, Gilardi E, Fazzini C, Carta $S$. Isoelectric focusing and immunoblotting analysis of thyroglobulin from different thyroid diseases. Thyroidal Clin Exp $1991 ; 3: 13-6$.

17. Zyznar ES. A rationale for the application of trasylol as a protease inhibitor in radioimmunoassay. Life Sci 1981; 28:1861-6

18. Laemmli UK. Cleavage of structural proteins during the assembly of the head of bacteriophage T4. Nature 1970; 227:680-5.

19. Pacini F, Antonelli A, Lari R, Gasperini L, Baschieri L, Pinchera $A$. Unsuspected parathyroid cysts diagnosed by measurements of thyroglobulin and parathyroid hormone concentrations in fluid aspirates. Ann Intern Med 1985; 102:793-4.

20. Pacini F, Fugazzola L, Lippi F, Ceccarelli C, Centoni R, Miccoli $\mathrm{P}$, et al. Detection of thyroglobulin in fine needle aspirates of nonthyroidal ncck masses: a clue to the diagnosis of metastatic differentiated thyroid cancer. J Clin Endocrinol Metab 1992; 74:1401-4.

21. Salabè GB. Aetiology of thyroid cancer: an epidemiological overview. Thyroidol Clin Exp 1994; 6:11-9.

\section{Received May 29/October 5, 1995}

Corresponding author: Prof. Giovanni Battista Salabè, Istituto di Medicina Sperimentale del C.N.R., V. le C. Marx 15-43, I-00137 Roma, Italy 
